\title{
Response to: Theoretical and methodological issues in the research on study addiction with relevance to the debate on conceptualising behavioural addictions: Atroszko (2018)
}

\author{
Odpowiedź na komentarz redakcyjny: Teoretyczne i metodologiczne zagadnienia dotyczqce \\ badania uzależnienia od uczenia się w kontekście debaty na temat konceptualizacji \\ uzależnień behawioralnych: Atroszko (2018)
}

Department of Health Sciences, School of Psychology, University of Florence, Florence, Italy

Correspondence: Yura Loscalzo, Department of Health Sciences, School of Psychology, University of Florence, Via di San Salvi 12 - Padiglione 26, 50135 Florence, Italy,

tel.. + 39055 2755071, fax: + 39055 2755390, e-mail:yura.loscalzo@gmail.com

Dogma is nothing else but the express prohibition of thinking. Ludwig Feuerbach

In this paper we respond to the commentary that Atroszko (2018) wrote on our paper entitled "The Bergen Study Addiction Scale: psychometric properties of the Italian version. A pilot study" (Loscalzo and Giannini, 2018), which have both been published in the previous issue of this journal.

Before providing answers to the points raised by Atroszko (2018), we want to highlight some critical aspects that we faced in reading his commentary: 1) Since Atroszko is the first author of the Bergen Study Addiction Scale (BStAS; Atroszko et al., 2015), we would have expected that he would have given more space to methodological and theoretical considerations about the psychometric issues we found regarding its Italian version (e.g., low percentage of variance explained by the factor, low factor loadings for items 1 and 2, lack of good divergent validity). This could contribute to improving the Italian version of the BStAS in a collaborative endeavour. 2) We believe he gave much more space to theoretical considerations related to the constructs of Study Addiction and Studyholism, which were not the focus of our psychometric paper he commented on. 3) While he emphasised the theory behind the constructs, he did not cite our own theoretical chapter about Studyholism (Loscalzo and Giannini, 2017a). Although this paper is not indexed on Scopus, we have sent Dr. Atroszko its full-length version at his request. Therefore, it would seem appropriate for this paper to be cited in the context of his commentary concerning an in-depth discussion of our
In sum, as a general impression we feel that the commentary is mainly off-topic. However, since we will be responding to that commentary, this present response will mainly focus on theory, rather than the psychometric aspects of the BStAS which were the focus of our paper in the last issue of this journal.

\section{A CLOSER LOOK INTO OCCAM'S RAZOR}

As it is expressed in the quotation reported by Atroszko (2018) at the beginning of his commentary, Occam's razor defines the rule of parsimony; however, it also specifies that "signs which serve no purpose are logically meaningless" (p. 276). In the context of problematic overstudying, the construct under discussion here, this means that, before discarding the definition of Studyholism (and the operationalisation of the construct), as suggested by Atroszko (2018), merely because it includes more elements than the construct of Study Addiction, we should evaluate whether Studyholism's additional and distinct elements (i.e., obsessive symptoms and low or high study engagement) are really purposeless or meaningless. Our studies suggest that this is not the case, that evaluating obsessive symptoms, and the level of study engagement, are quite meaningful and important.

In our theoretical article we posited that the additional component of Study Engagement is critical, as it allows distinguishing between Engaged Studyholics (characterised by high levels of both obsessive-compulsive symptoms and study engagement) and Disengaged Studyholics (who have high levels of obsessive-compulsive symptoms, but low study engagement), who may have different 
relationships with the same antecedents and outcomes (Loscalzo and Giannini, 2017a). This theoretical proposition has been recently supported by research on a large sample of Italian college students (Loscalzo, 2018). Additionally, it is worth noting that we followed the same methodological approach used by Atroszko et al. (2015) for specifying our operationalization of problematic overstudying: we critically analysed previous research and theoretical developments in the workaholism literature. However, our review of the literature led to a different model from the addiction one (Loscalzo and Giannini, 2017b), and our model has already found support by the study of Spagnoli et al. (2018).

In sum, we re-affirm that even if Study Addiction and Studyholism are both related to the same problem behaviour, namely problematic overstudying (the term we prefer to use when not referring specifically to the Study Addiction or Studyholism conceptualisations), it is necessary to distinguish between the two due to their significant differences in their theoretical conceptualisations (i.e., as an obsessivecompulsive-related disorder - OCD-related disorder - versus a behavioural addiction, and the inclusion of study engagement in the definition of Studyholism).

The research literature on problematic overstudying is recent and very scant. Much work has to be done before arguing whether one of the two constructs is better than the other. A mere analogy with workaholism or work addiction is likely not sufficient to discard either of the two definitions prematurely and without proper testing. This is especially pertinent in the light of the fact that the scientific community still lacks a shared definition of workaholism itself (Giannini and Loscalzo, 2016; Loscalzo and Giannini, 2017b, 2015).

\section{STUDYHOLISM AS AN OCD-RELATED DISORDER}

Concerning the points that Atroszko (2018) raises about the presence of obsessive-compulsive symptoms as one of the main differences between Studyholism and Study Addiction, it is worthwhile noting that the papers that the author referenced are nearly all published in Polish (and one of them in fact seems to refer to work addiction) and in journals not indexed on Scopus. This prevents the spread of these papers in the scientific literature and their inclusion in scholars' works, including ours. The only exception is the Atroszko et al. (2015) paper, published in English and in an indexed journal, which, however, does not take into account perfectionism or other obsessive symptoms; conscientiousness and neuroticism, which it refers to, are personality traits and not OCD symptoms. In addition, compulsiveness has been obviously analysed (or at least theoretically considered) in the Study Addiction literature, since compulsion is an orthogonal factor across disorders, including OCD and substance use disorders (Cuzen and Stein, 2014). Hence, it is crucial to specify that for us the main differentiation between the two constructs relies on the fact, as evident in both Atroszko (2018) and Atroszko et al. (2015), that Study Addiction is defined as a behavioural addiction, while we believe Studyholism is defined as an OCD-related disorder (Loscalzo and Giannini, 2017a; Loscalzo et al., 2018). In other words, while Atroszko (2018) suggests that "Study Addiction has been explicitly linked to compulsiveness and obsessiveness, perfectionistic tendencies and dysfunctional perfectionism" (p. 277, italics added), we strongly suggest that instead obsessive symptoms are an intrinsic component of Studyholism.

Next, concerning Atroszko (2018)'s reference to an instrument he created simultaneously with the BStAS, the Multidimensional Inventory - Learning Profile of a Student, the papers referenced are again tricky to find through searching scientific databases and are mainly written in Polish. However, there does not seem to be a paper devoted specifically to the psychometric properties of the instrument, the items are not provided, and the Atroszko et al. (2015) paper does not refer to the development of this instrument, simply stating that the BStAS is an adaption of the Bergen Work Addiction Scale (BWAS; Andreassen et al., 2012).

Finally, regarding our conceptualisation of Studyholism as an OCD-related disorder, there is another point to clarify regarding Obsessive-Compulsive Personality Disorder (OCPD). In addition to the fact that one of the papers referenced in this section of the commentary seems to refer to Facebook Addiction (and not to Work Addiction, as Atroszko states), we want to underline that Studyholism, OCD, and OCPD are three distinct clinical diagnoses which should not be collapsed (while of course taking into account the usual comorbidity of psychological disorders). In line with the DSM-5 (American Psychiatric Association, 2013) we specified that in order to make a diagnosis of Studyholism, any other clinical diagnoses that might explain Studyholism symptoms should be excluded, including OCPD (Loscalzo and Giannini, 2017a, p. 13), being sure that "perfectionism and high involvement in study are not explainable by obsessive-compulsive personality disorder." Along the same lines, Attention Deficit Hyperactive Disorder (ADHD), as well as Specific Learning Disabilities (SLD), which are more properly classified as neurodevelopment disorders (American Psychiatric Association, 2013), have to be excluded in order to make a diagnosis of Studyholism as well.

\section{STUDYHOLISM WITHIN THE HEAVY STUDY INVESTMENT FRAMEWORK}

Another relevant difference between Studyholism and Study Addiction concerns the theoretical frameworks in which they were developed. While Atroszko et al. (2015) conceptualise problematic overstudying within the addiction framework and refer to the seven core components of addiction, we make reference to the Heavy Study Investment (HSI) 
model, derived from the Heavy Work Investment (HWI) model proposed by Snir and Harpaz (2012) in the workaholism literature. More specifically, we have suggested distinguishing among three kinds of hard-working students based on their levels of high/low studyholism/study engagement: Disengaged Studyholics, Engaged Studyholics, and Engaged Students (Loscalzo and Giannini, 2017a).

Regarding this point, Atroszko (2018) writes that in the literature the differences between study/work engagement and study/work addiction are already well acknowledged and that to suggest that there is a difference between our constructs based on the HSI model is incorrect.

However, it seems that he overlooked an essential element of our theory: we suggest that Studyholism/Workaholism and Study/Work Engagement are two different constructs that, however, should be crossed in order to identify different kinds of heavy study/work investors, and that these different kinds of students/workers may have different relationships with the same antecedents and outcomes (Loscalzo and Giannini, 2017b, 2017a). Moreover, it also appears that Atroszko (2018) does not take into account the fact that, even if scholars generally did agree in distinguishing between work engagement and workaholism, we recently published our own workaholism model (which distinguishes between Disengaged Workaholics and Engaged Workaholics and hence crosses the two constructs) in a work and organisational psychology journal (Loscalzo and Giannini, 2017b). Moreover, despite its being published only recently, this model has already found support in one Italian study (Spagnoli et al., 2018).

In sum, since our model questions previous theoretical positions regarding workaholism and work engagement, we stress again that referring to the HSI/HWI model is actually a critical difference when our approach is compared to Study and Work Addiction theory.

\section{PROBLEMATIC OVERSTUDYING FROM AN INTERNALISING/EXTERNALISING PERSPECTIVE}

It should be remembered that every time one tries to classify some entities, this always involves an oversimplification; for some of those entities, it may also be difficult choosing the category in which they should be included; this is the cost of categorisation. Nevertheless, it is a useful cognitive process.

Keeping this in mind, no matter what specific definition one wants to use for defining externalising and internalising disorders, we believe that we might agree that addictions are usually recognised as externalising disorders; Atroszko actually acknowledges this in his commentary referring to Krueger et al. (2005). This applies whether referring to externalising disorders as disruptive behaviour disorders, as socially deviant, or as a discipline problem (Atroszko, 2018). Hence, including addictions to substances in the ex- problem behaviours defined as behavioural addictions such as Study Addiction based on shared core addiction components - seems correct to us.

Atroszko's (2018) argument that Study Addiction seems to have almost nothing in common with the externalising disorders, followed by his listing of various suggested features in the study addicted (such as conscientiousness, diligence, and conformity), in our opinion actually confirm our suggestion that problematic overstudying is indeed not an addiction because it shares more phenomenological features with internalising disorders, such as OCD.

Finally, it should also be noted that we believe (and have written: Loscalzo and Giannini, 2017a, 2018; Loscalzo et al., 2018) that problematic overstudying is more similar to an obsession (or internalising disorders) than to addiction (or externalising disorders). This implies that, even if the internalising/externalising perspective may be useful in distinguishing Study Addiction (Atroszko et al., 2015) and Studyholism (Loscalzo and Giannini, 2017a) as the respective authors have conceptualised them, we also acknowledge that it is almost impossible to find in reality a pure internalising or externalising disorder, also due to comorbidity issues. In line with this we have also stated that the BStAS could assess one internalising symptom (i.e., obsession) through its "salience" item, even though this has been proposed by Atroszko et al. (2015) as a core addiction component (Loscalzo and Giannini, 2017a).

\section{WHY ARE WE USING THE TERM "STUDYHOLISM," WHICH MAY RECALL ALCOHOLISM?}

Having presented the main features of our definition of problematic overstudying, we can now answer the question posed by Atroszko (2018) and briefly summarised above. We can simply answer that we prefer the term Studyholism to Study Addiction for the same reason that he prefers the term work addiction to workaholism: "workaholism" is a more generic term, while "work addiction" helps to emphasise the addiction framework (Griffiths et al., 2018).

As stated before (Loscalzo and Giannini, 2017a), the term "Studyholism," because it is more general, better mirrors our theory; while allowing continuity with the workaholism literature, it also allows us to avoid the reduction of our construct to addiction and negative symptoms alone. Instead, we emphasise its OCD-related symptoms and the possibility of its co-occurrence with high study engagement, a positive component. For the same reasons we prefer the term workaholism to work addiction (Loscalzo and Giannini, $2017 b$, in press a).

Using different names for Studyholism and Study Addiction is imperative for us. Doing so allows some clarity in the problematic overstudying literature and helps avoid the confusion surrounding the workaholism literature, which has been characterised by many different definitions under the 
umbrella terms workaholism and work addiction (usually used interchangeably), something that has prevented developing cumulative knowledge about the construct (Giannini and Loscalzo, 2016; Loscalzo and Giannini, 2017b, 2015).

\section{THE ITALIAN BStAS}

As stated at the beginning of this paper, we would have expected more consideration in the Commentary of psychometric issues of the Italian version of the BStAS, which is the focus of our paper on which Atroszko's (2018) commentary was based. However, what seems more critical to Atroszko concerns the analyses we conducted using Exploratory (EFA) and Confirmatory (CFA) Factor Analyses.

Regarding EFA, we agree that it is usually not conducted in the context of instruments supported by an explicitly stated theory and consistent previous data related to different cross-cultural samples. Indeed, in our previous works - where these conditions were applicable, such as in the case of the Utrecht Work Engagement Scale - Student and short version (UWES-S-9; Schaufeli and Bakker, 2004) and perfectionism scales - we performed CFAs only and not EFA (Loscalzo and Giannini, in press b; Loscalzo et al., in press). However, when validating the Edinburgh Postnatal Depression Scale (EPDS; Cox et al., 1987) on a sample of Italian fathers, we instead performed a preliminary EFA, followed by a CFA (Loscalzo et al., 2015) because there were only a few previous studies on male populations.

Along the same lines, we performed EFA as a first step for analysing the BStAS on Italian students since we expected to find some problematic items. Even if the BStAS is grounded in addiction theory, the instrument includes items referring to some core addiction components suggested as being not easily operationalised in the behavioural addiction field (Billieux et al., 2015; Ko and Yen, 2015). In addition, the BStAS has actually only been currently evaluated in Polish and Norwegian samples, with significantly different fit indexes found (Atroszko et al., 2015).

We agree that an additional CFA should be conducted in order to cross-validate the modified model, and we have indeed written that the Italian BStAS should be analysed further (Loscalzo and Giannini, 2018). Moreover, the title of the paper itself includes that it reports "a pilot study," which implies that further analyses are needed.

Regarding the suggestion to create two structural models according to the Studyholism and Study Addiction theories and to compare their fit, we believe that this is not technically possible for two main reasons. First, our preliminary assumption that Studyholism includes both addiction and obsessive symptoms has now been discarded in favour of conceptualising it as a prevalently OCD-related disorder (Loscalzo and Giannini, 2017a; Loscalzo et al., 2018). Secondly, the BStAS, created based on the seven core addiction components, does not have items specifically intended to tap obsessions and related symptoms, and there are no compulsion items, which could be used in both the OCD and addiction frameworks as representing an orthogonal factor (Cuzen and Stein, 2014). Hence, using the BStAS items for testing the two different theorisations is not feasible. However, it is interesting to note that item 1 (salience), which has been suggested as the only one which could address obsessive symptoms (Loscalzo and Giannini, 2017a), is the most problematic one, in accordance with our results (Loscalzo and Giannini, 2018).

As minor considerations, Atroszko (2018) wrote that we suggest that the Italian BStAS has problematic structure as if this is something that was just discovered. However, we actually wrote that we expected these issues: "the issue with the tolerance item (item 2) is hardly surprising, as it is in line with the recent criticism about the aprioristic and confirmatory application of the addiction model to excessive behaviours" (Loscalzo and Giannini, 2018, p. 274). Finally, Atroszko (2018) suggests that we should publish the Italian version of the BStAS. However, we have already sent him our Italian translation (which has been developed using the back-translation process); moreover, as required by scientific standards and ethics, we are obviously available to provide interested researchers with our Italian translation (and authorisation to use it) upon request.

\section{CONCLUSIONS}

The point we want to highlight the most is that current knowledge about problematic overstudying is still too scant to allow us to define this new potential clinical condition as being primarily a behavioural addiction (Atroszko et al., 2015) or as primarily an OCD-related disorder and including a distinction among Engaged and Disengaged Studyholics (Loscalzo and Giannini, 2017a).

Atroszko (2018) states that both theoretical models and empirical data are consistent with his view of problematic overstudying as an addiction-like disorder. However, we suggest the opposite. Indeed, our critical and systematic review of the workaholism literature (Loscalzo and Giannini, 2017b; supported by Spagnoli et al., 2018) and our empirical research (Loscalzo, 2018) indicates that problematic overstudying can be conceptualised as an OCD-related disorder, and that it is important to distinguish between Engaged and Disengaged Studyholics. Moreover, Atroszko (2018) makes the assertion that Study Addiction "presents itself phenomenologically as an addiction, but individual characteristics of study addicts are almost opposite to that of substance abusers or pathological gamblers" (p. 280); in our view, this assertion actually supports our formulation that problematic overstudying is not an addiction, as it shares more features with the internalising disorders, including OCD. The DSM-5 (American Psychiatric Association, 2013) included Gambling Disorder in the substance-related and addictive disorders section based on the shared features in these disorders, and specifically due to the observation of 
brain activation of the reward system in both of the clinical conditions. Thus, we speculate that in order for it to be classified as a behavioural addiction by the official manual of mental disorders, problematic overstudying would need to demonstrate a larger number of common features with substance use disorders and gambling disorder (the only behavioural addiction formally recognized now), than in comparison to internalising disorders.

In this context, we also believe that it is critical to avoid being closed in each of our own theoretical positions. We should rather critically and scientifically evaluate both of our theoretical structures by means of research, in order to gather more data which would allow understanding whether problematic overstudying is actually better conceptualised as an addiction (Atroszko et al., 2015), an OCD-related disorder (Loscalzo and Giannini, 2017a; Loscalzo et al., 2018), or as something else.

We conclude our paper pointing out that we believe that Occam's razor is useful in scientific research; however, it should not lead to discarding alternative hypotheses and explanations - before they have been evaluated critically and tested scientifically - only based on the number of elements the explanations contain. More complex definitions should be discarded in favour of simpler ones only when the two competing theories explicitly make the same predictions and the additional components serve no explanatory purpose. In the specific case of problematic overstudying, we do not believe that Occam's razor is applicable. Our theoretical formulation adds elements not taken into account by Atroszko et al. (2015), such as the distinction among different types of Studyholics (Loscalzo and Giannini, 2017a). Moreover, as we have noted here, we believe that our research actually shows that problematic overstudying may best be conceptualised as an OCD-related disorder, and that the distinction between Engaged and Disengaged Studyholics may prove useful for both preventive and clinical purposes (Loscalzo, 2018).

\section{Conflict of interest}

The authors do not report any financial or personal connections with other persons or organisations which might negatively affect the content of this publication and/or claim authorship rights to this publication.

\section{References}

American Psychiatric Association: Diagnostic and Statistical Manual of Mental Disorders. Fifth edition. DSM-5. American Psychiatric Publishing, Washington, DC 2013.

Andreassen CS, Griffiths MD, Hetland J et al.: Development of a work addiction scale. Scand J Psychol 2012; 53: 265-272.

Atroszko PA: Commentary on: The Bergen Study Addiction Scale: psychometric properties of the Italian version. A pilot study. Theoretical and methodological issues in the research on study addiction with relevance to the debate on conceptualising behavioural addictions. Psychiatr Psychol Klin 2018; 18: 276-282.

Atroszko PA, Andreassen CS, Griffiths MD et al.: Study addiction a new area of psychological study: conceptualization, assessment, and preliminary empirical findings. J Behav Addict 2015; 4: 75-84.
Billieux J, Schimmenti A, Khazaal Y et al: Are we overpathologizing everyday life? A tenable blueprint for behavioral addiction research. J Behav Addict 2015; 4: 119-123.

Cox JL, Holden JM, Sagovsky R: Detection of postnatal depression. Development of the 10-item Edinburgh Postnatal Depression Scale. Br J Psychiatry 1987; 150: 782-786.

Cuzen NL, Stein DJ: Behavioral addiction: the nexus of impulsivity and compulsivity. In: Rosenberg KP, Feder LC (eds.): Behavioral Addictions: Criteria, Evidence, and Treatment. Academic Press, Elsevier, London 2014: 19-34.

Giannini M, Loscalzo Y: Workaholism: health risk and prevention in the organizations. In: Di Fabio A (ed.): Neuroticism: Characteristics, Impact on Job Performance and Health Outcomes. Nova Science Publishers, New York 2016: 49-60.

Griffiths MD, Demetrovics, Atroszko PA: Ten myths about work addiction. J Behav Addict 2018: 1-13.

Ko CH, Yen JY: Commentary on: Are we overpathologizing everyday life? A tenable blueprint for behavioral addiction research. Excessive behaviors are not necessarily addictive behaviors. J Behav Addict 2015; 4: 130-131.

Krueger RF, Markon KE, Patrick CJ et al.: Externalizing psychopathology in adulthood: a dimensional-spectrum conceptualization and its implications for DSM-V. J Abnorm Psychol 2005; 114: 537-550.

Loscalzo Y: Studyholism: A New Potential Clinical Condition. Unpublished $\mathrm{PhD}$ thesis, University of Florence, Florence 2018.

Loscalzo Y, Giannini M: Clinical conceptualization of workaholism: a comprehensive model. Organizational Psychology Review 2017b; 7: 306-329.

Loscalzo Y, Giannini M: Study engagement in Italian university students: a confirmatory factor analysis of the Utrecht Work Engagement Scale-Student version. Soc Indic Res. In press b.

Loscalzo Y, Giannini M: Studyholism or Study Addiction? A comprehensive model for a possible new clinical condition. In: Columbus AM (ed.): Advances in Psychological Research. Nova Science Publishers, New York 2017a: 19-37.

Loscalzo Y, Giannini M: The Bergen Study Addiction Scale: psychometric properties of the Italian version. A pilot study. Psychiatr Psychol Klin 2018; 18: 271-275.

Loscalzo Y, Giannini M: What type of worker are you? Work-Related Inventory (WI-10): a comprehensive instrument for the measurement of workaholism. WORK In press a.

Loscalzo Y, Giannini M: Workaholism: Cosa cè di nuovo? [Workaholism: what's new?]. Counseling 2015; 8 (3).

Loscalzo Y, Giannini M, Contena B et al: The Edinburgh Postnatal Depression Scale for Fathers: a contribution to the validation for an Italian sample. Gen Hosp Psychiatry 2015; 37: 251-256.

Loscalzo Y, Giannini M, Golonka K: Studyholism Inventory (SI-10): psychometric properties of the Italian and Polish versions. In: Ostrowski TM, Piasecka B, Gerc K (eds.): Resilience and Health. Challenges for an Individual, Family and Community. Jagiellonian University Press, Kraków 2018: 205-217.

Loscalzo Y, Rice SPM, Giannini M et al.: Perfectionism and academic performance in Italian college students. J Psychoeduc Assess. In press.

Schaufeli WB, Bakker AB: Test Manual for the Utrecht Work Engagement Scale. Unpublished manuscript, Utrecht University, The Netherlands 2004.

Snir R, Harpaz I: Beyond workaholism: towards a general model of heavy work investment. HRMR 2012; 22: 232-243.

Spagnoli P, Balducci C, Scafuri Kovalchuk L et al.: Are engaged workaholics protected against job-related negative affect and anxiety before sleep? A study of the moderating role of gender. Int J Environ Res Public Health 2018; 15: E1996. 